\title{
Inverted Meckel's diverticulum mimicking an ulcerated pedunculated polyp: detection by single-balloon enteroscopy
}

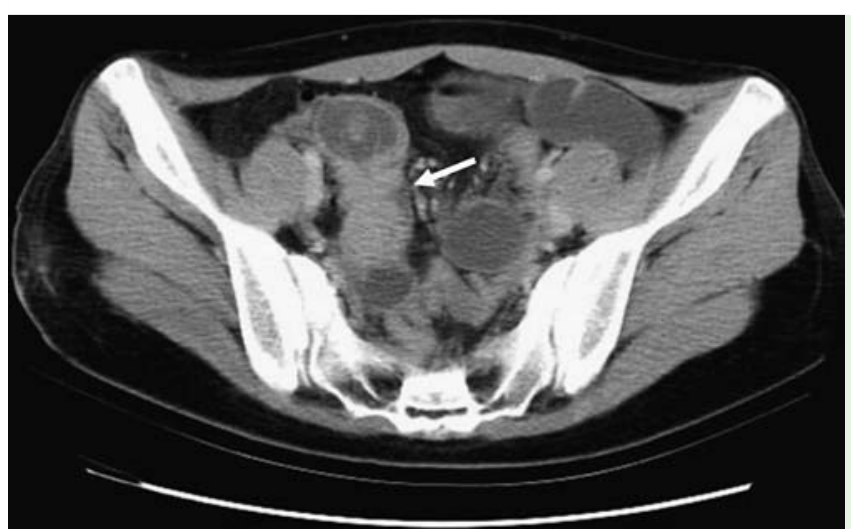

Fig. 1 Abdominal computed tomography revealed one heterogeneous lesion with soft tissue and accumulation of fluid over the distal ileum (arrow).

A 19-year-old woman was referred to our hospital because of recurrent obscure gastrointestinal bleeding. Abdominal computed tomography revealed one heterogeneous lesion with soft tissue and accumulation of fluid over the distal ileum ( $\bullet$ Fig. 1 ).

Physical examinations showed mild tenderness in the right lower quadrant region of abdomen, and laboratory data revealed microcytic anemia. Single-balloon enteroscopy with an anal approach showed one ulcerated pedunculated polyp (about $2 \mathrm{~cm}$ in size) with a long stalk located at around the distal ileum ( Fig. $\mathbf{2 a , b}$; - Video 1).

Polypectomy was performed during enteroscopy ( Fig. 2c). One diverticularlike orifice occurred after polypectomy, and one small hole on the tip of this diverticulum was visualized. The woman received emergent laparotomy because of iatrogenic gut perforation. The operation disclosed one diverticulum with iatrogenic perforation about $60 \mathrm{~cm}$ from the ileocecal valve ( $\bullet$ Fig. 3 a).

Segmental resection of the ileum was performed. The pathologic examination of specimens from laparotomy and polypectomy confirmed the diagnosis of Meckel's diverticulum with ectopic pancreatic tissue ( $\bullet$ Fig. 3b) and gastric tissue $(\bullet$ Fig. 3c) with ulceration.
Meckel's diverticulum is the most common congenital anomaly of the gastrointestinal tract $(1 \%-3 \%$ of the population); it is generally asymptomatic. Bleeding is the most common complication, especially in children. However, accurate diagnosis remains difficult. In addition to conventional Technetium-99 $\mathrm{m}$ pertechnetate scintigraphy, capsule or balloon-assisted enteroscopy is another diagnostic tool to directly observe the diverticulum [1-3]. Inverted Meckel's diverticulum is extremely rare, especially that containing both pancreatic and gastric tissues [4,5]. In the present case, the inverted Meckel's diverticulum with ectopic tissues was clearly viewed by single-balloon enteroscopy, but this lesion mimicked an ulcerated pedunculated polyp. Polypectomy caused subsequent gut perforation. Therefore, inverted Meckel's diverticulum should be considered and treated carefully in a patient with an elongated pedunculated polyp in the distal ileum.

\section{Endoscopy_UCTN_Code_CPL_1AI_2AD}

\section{Competing interests: None}

\section{Video 1}

Single-balloon enteroscopy with an anal approach revealed one elongated pedunculated polyp with ulceration over the distal ileum.
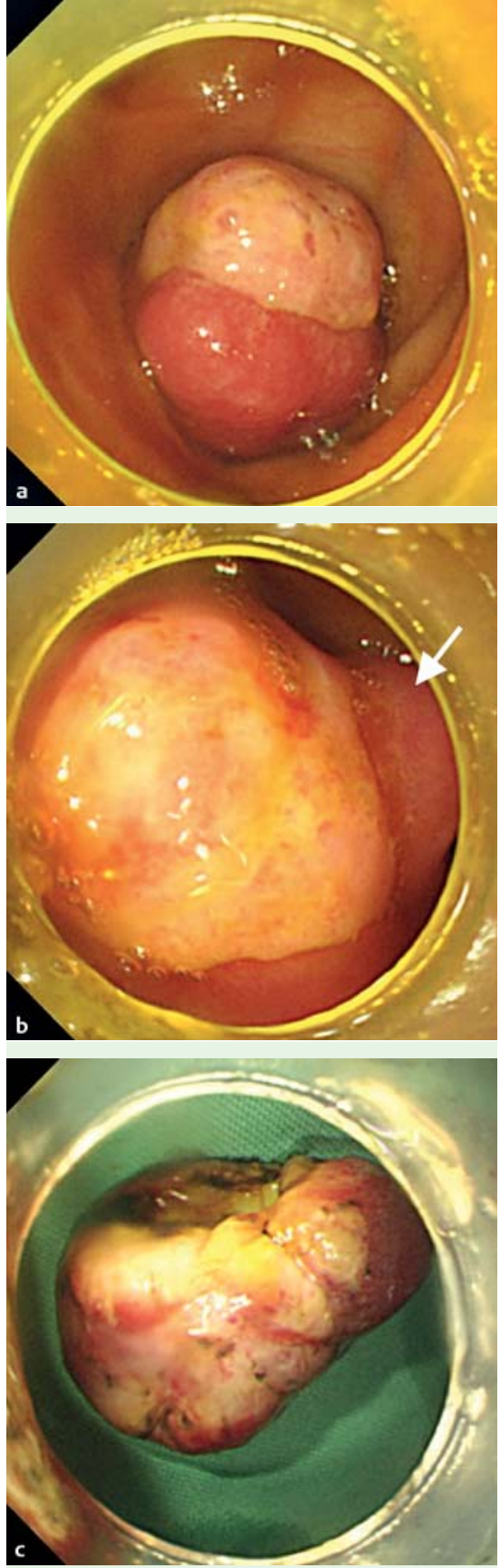

Fig. 2 a, b Enteroscopy showed one ulcerated polyp with a long stalk located at around the distal ileum. The arrow indicates the long stalk of the polyp. c The specimen of resected polyp. 

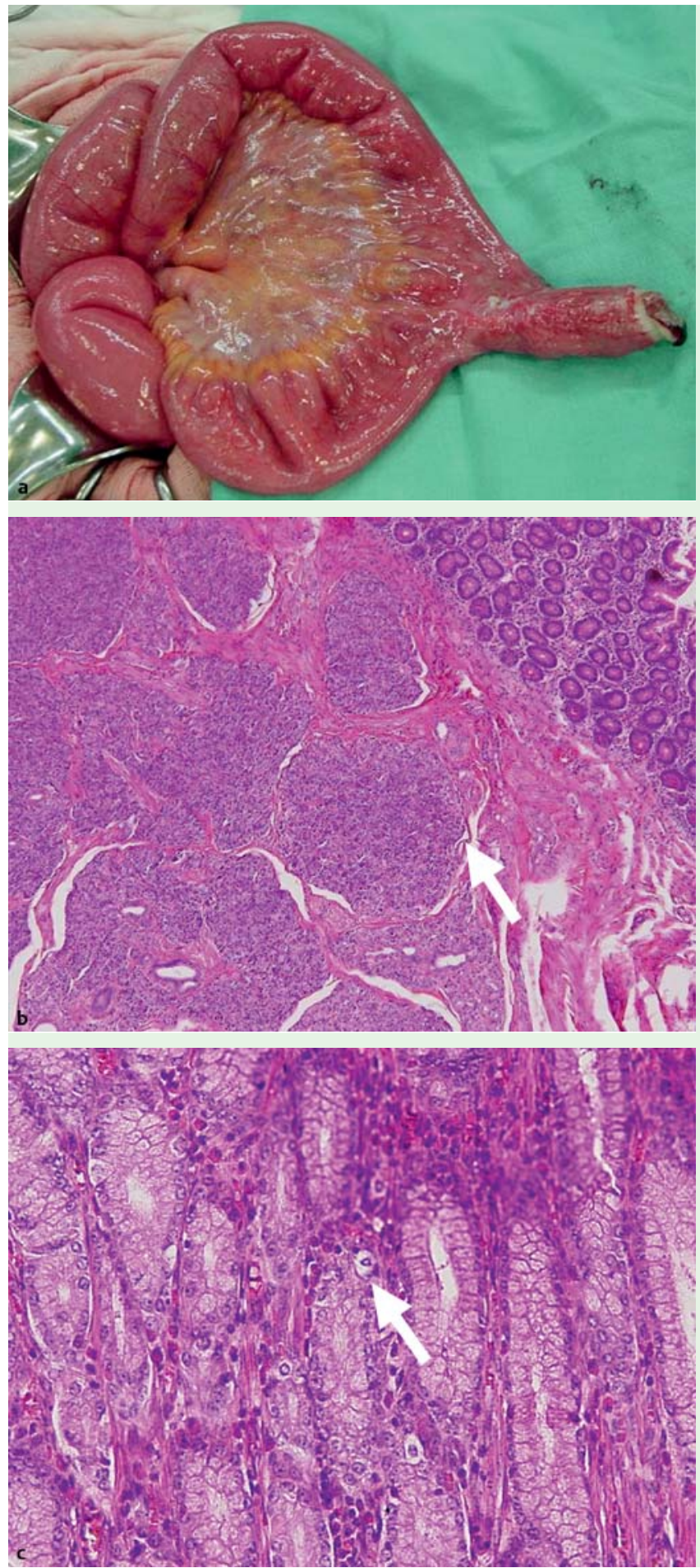

Fig. 3 a Operation findings disclosed one diverticulum with perforation about $60 \mathrm{~cm}$ from the ileocecal valve. b Pathologic examinations showed ectopic pancreatic tissue within the resected polyp. The arrow indicates the islets of Langerhans. c Pathologic examinations revealed ectopic gastric tissue within the resected polyp. The arrow indicates the gastric glands with parietal cells.
T.-Y. Huang ${ }^{1}$, Y.-C. Liu ${ }^{2}$, H.-S. Lee ${ }^{3}$, H.-C. Chu ${ }^{1}$, P.-J. Chen ${ }^{1}$, J.-W. Weng ${ }^{1}$, C.-K. Fu ${ }^{1}$, K.-F. Hsu ${ }^{2}$

${ }^{1}$ Division of Gastroenterology, Tri-Service General Hospital, Taipei, Taiwan, Republic of China

2 Department of Surgery, Tri-Service General Hospital, Taipei, Taiwan, Republic of China

3 Department of Pathology, Tri-Service General Hospital, Taipei, Taiwan, Republic of China

\section{References}

1 Moon JH, Park CH, Kim JH et al. Meckel's diverticulum bleeding detected by capsule endoscopy. Gastrointest Endosc 2006; 63: $702-703$

2 Honda K, Mizutani T, Higuchi N et al. A Meckel's diverticulum with an ileal ulcer detected with double-balloon enteroscopy. Endoscopy 2007; 39: $160-0$

3 Shinozaki S, Yamamoto H, Ohnishi H et al. Endoscopic observation of Meckel's diverticulum by double balloon endoscopy: report of five cases. J Gastroenterol Hepatol 2008; 23: 308-311

4 Yan SL, Chou DA, Wu CS. Inverted Meckel's diverticulum: a rare cause of obscure GI bleeding. Gastrointest Endosc 2011; 73: 611-612

5 Kopacova M, Vykouril L, Vacek $Z$ et al. Inverted Meckel's diverticulum with ectopic pancreatic tissue as a source of severe gastrointestinal bleeding. J Gastrointest Surg 2010; 14: 578-581

\section{Bibliography}

DOI 10.1055/s-0030-1256528

Endoscopy 2011; 43: E244 -E245

(c) Georg Thieme Verlag KG Stuttgart · New York . ISSN 0013-726X

\section{Corresponding author}

\section{T.-Y. Huang, MD, PhD}

Division of Gastroenterology

Department of Internal Medicine

Tri-Service General Hospital

325 , Section 2, Cheng-Kung Road

Taipei 114

Taiwan

Republic of China

Fax: +886-2-87927139

teinyu.chun@msa.hinet.net 